Original

Article

\title{
Coping preferences of head and neck cancer patients - Indian context
}

\author{
Vidhubala E, Latha', Ravikannan $\mathbf{R}^{2}$, Mani $\mathbf{C S}^{2}$, Karthikesh $\mathbf{M}^{3}$ \\ Departments of Psycho-oncology, Cancer Institute (WIA), Adyar, Chennai, ${ }^{1}$ Psychology, University of \\ Madras, Chennai, ${ }^{2}$ Surgical Oncology, Cancer Institute (WIA), Adyar, Chennai, ${ }^{3}$ Surgical Oncology, \\ Ramakrishna Mission Hospital, Coimbatore, India
}

Correspondence to: E. Vidhubala, E-mail: caninst@md2.vsnl.net.in

\section{Abstract}

BACKGROUND: Cancer is a major health-related stress and demands adequate coping. Patients with head and neck carcinoma (HNC) often face exhaustive and debilitating treatment as well as physical and functional residual effects such as disfigurement, compromised speech, dry mouth and difficulty in swallowing. Understanding how patients cope with these challenges is important in comprehensive care of patients with HNC. OBJECTIVE: To assess and evaluate the coping preferences of head and neck cancer patients. MATERIALS AND METHODS: Towards this goal, a prospective study was conducted at the Cancer Institute (WIA), Chennai. 176 HNC patients participated in the study. The age group ranged from 19 to 87 years. The questionnaire used for assessing coping preferences was Jalowiec coping preference scale containing 40 items, with responses ranging on a 5-point scale. The variables chosen were treatment, site, education, survival, age and gender. STATISTICAL ANALYSIS USED: SPSS 9.0 version was used for both descriptive and multivariate analysis. RESULTS: No significant difference was observed in the preference of Emotion-Oriented Coping (EOC) in relation to age, treatment, site, education and survival. Treatment, site, education and gender showed significant differences in the preference of Problem-Oriented Coping (POC). There was, however, no difference in the preference of POC among the patients with different survival periods and age. CONCLUSION: In conclusion, HNC patients adapt both EOC and POC during the course of the illness. Literates, males and patients subjected to different modalities of treatment preferred more of POC compared to other groups.

Key Words: Education, emotion-oriented coping, head and neck cancer, problem-oriented coping, site, treatment

Patients with head and neck carcinoma (HNC) often face exhaustive and debilitating treatment as well as physical and functional residual effects such as disfigurement, compromised speech, dry mouth and difficulty in swallowing. Understanding how patients cope with these challenges is important in comprehensive care of patients with HNC. A preference of coping strategies is an acquired style, which can be influenced by exposure to the stress of cancer. ${ }^{[1]}$

From the earlier studies, it can be understood that during the course of cancer diagnosis and treatment, HNC patients usually adopt a wide range of coping strategies that can be broadly classified as problem- or emotion-oriented. ${ }^{[2]}$ Problem-oriented coping (POC) aims to make direct changes in the environment so that the situation can be dealt with more effectively. Emotion-oriented coping (EOC) seeks to make the person feel better by reducing the emotional distress felt.

POC leads to better adjustment and thereby improve Quality of life (QOL) of cancer patients. ${ }^{[3]}$ EOC, on the other hand, is associated with higher anxiety and depression and a worse QOL. ${ }^{[4-7]}$ Teaching coping strategies for head and neck cancer patients improves 
physical and social functioning and global QOL and reduces fatigue, sleep disturbances and depressive symptoms. ${ }^{[6]}$

Commonest concerns identified among the HNC patients were about the future, subjective physical evaluation, finances, being upset, communication, current illness and inability to do things. The commonest coping mechanisms used were helplessness and fatalism. These ineffective EOC mechanisms lead to incomplete resolution of these concerns. ${ }^{[3]}$

A study by List revealed that social-support-seeking behavior represents the greatest proportion of the total coping effort. The use of avoidant coping, both cognitive and behavioral escape, was associated with poorer overall QOL. ${ }^{[8]}$ A study on nasopharyngeal cancer patients reported that positive EOC styles were positively correlated to QOL and negative EOC correlated negatively. ${ }^{[9]}$ In contrast to other studies, POC styles were not statistically correlated to QOL among patients in this study. ${ }^{[9]} \mathrm{A}$ study by Relic revealed that family support could boost coping ability by resorting to POC. Deficits in support were associated with a low overall QOL.[10]

Understanding how patients cope with these challenges is important in the comprehensive care of patients with cancer. If the coping preferences and variables that affect the coping styles were identified, it would be useful in the rehabilitation process and to design appropriate intervention strategies. The present study was undertaken to assess and evaluate the coping preference of head and neck cancer patients, either problem- or emotion-focused, with regard to site of disease, educational status, treatment modalities, period of survival, age and gender. The study was reviewed by the local review board of the Institute and it received the clearance from the ethical committee. Informed consents were obtained from patients.

\section{Methodology}

The sample was collected from the Regional cancer centre, Chennai. One hundred and seventy-six head and neck cancer patients who attended the OPD for a period of six months were included. The sample description is given in [Table 1].

\section{Inclusion criteria}

- Only head and neck cancer patients.

- Irrespective of demographic variables and biomedical variables, all the patients who attended the OPD for the specific period.

\begin{tabular}{|c|c|c|c|c|c|}
\hline \multirow[t]{2}{*}{ Site } & \multirow[t]{2}{*}{$\mathrm{N}$} & \multicolumn{2}{|c|}{ Education } & \multicolumn{2}{|c|}{ Sex } \\
\hline & & III & Lit & $\mathrm{M}$ & $F$ \\
\hline Cheek & 44 & 29 & 15 & 21 & 23 \\
\hline Tongue & 20 & 5 & 15 & 13 & 7 \\
\hline Oropharynx & 11 & 0 & 11 & 10 & 1 \\
\hline Hypopharynx & 13 & 6 & 7 & 4 & 9 \\
\hline Thyroid & 33 & 4 & 29 & 9 & 24 \\
\hline Others* & 33 & 12 & 21 & 25 & 8 \\
\hline Larynx & 22 & 6 & 16 & 19 & 3 \\
\hline Total & 176 & 62 & 114 & 101 & 75 \\
\hline
\end{tabular}

\section{Exclusion criteria}

- Cancer patients other than head and neck cancer.

- Patients who could not respond at all due to poor general condition.

The age ranged from 19 to 87 years. Among 176 patients, 101 were males and 75 were females. Literates and illiterates and treated and untreated patients were included. Survival period ranged from 1 month to 17 years.

\section{Tools used}

The questionnaire used for assessing coping preferences was Jalowiec Coping Scale ${ }^{[1]}$ containing 40 items with responses given on a 5 -point scale. The $1-5$ stand for: 1 - Never, 2 - Very Rarely, 3 - Sometimes 4 - Very Often, 5 - Always.

The questionnaire had 25 problem-focused items and 15 emotion-focused items. The reliability and validity of the questionnaire is well established with a concurrent validity of $\mathrm{r}=0.84$. Patients were engaged to fill up the questionnaire. For those without sufficient educational background, the tool was administered and the response for each item was elicited from the patients by the first author.

\section{Statistics used}

The data collected from 176 patients were analyzed by using the Statistical Package for Social Science (version 9.0). ANOVA and independent sample ' $t$ ' test were used.

\section{Results}

Analysis of variance test was used initially to find out 
the differences in POC and EOC in relation to treatment, site, education, survival and age [Table 2].

Among head and neck cancer patients, no salient difference was found in the EOC, irrespective of site of disease, educational status, treatment modalities, period of survival and age. This shows that irrespective of the above-mentioned biomedical and demographic variables, all the cancer patients tend to react emotionally to the disease.

With regard to POC, significant differences were found between treatment modalities, site and education groups at $P=0.04, P<0.01, P<0.01$ levels respectively. The period of survival and age were found to be immaterial in coping strategies.

This data was further analysed to find out the differences within the treatment modalities, education and site of disease, where significant differences were found in ANOVA.

\section{Treatment [Table 3]}

Patients $(M=77.72)$ undergoing surgery and radiation therapy with surgery $(M=80.59)$ have higher POC than newly diagnosed and terminally ill patients. Compared with newly diagnosed patients and treated patients, palliative care patients scored less in POC. This is because the palliative care patients do not have any hope for a cure. They do not have any other choice and this state of hopelessness might have lessened their preference for POC. Similarly, compared to the treated patients the newly diagnosed patients scored less in POC. This might be due to the emotional distress and trauma felt by the patients immediately after the diagnosis and also because they were still unaware of the treatment possibilities.

\section{Education [Table 4]}

It was observed that literates had comparatively high preference for POC than the illiterates. It is also to be observed from the table that the mean scores of POC is increasing with increase in educational status, i.e,

Table 2: ANOVA shows the coping preference of the head and neck cancer patients by their treatment level, educational status, age and site

\begin{tabular}{lccccccc}
\hline Source & Variable & SS & Df & Mean square & F-value & $P$-value & Sig. \\
\hline Treatment & POC & 2197.01 & 4 & 549.25 & 2.45 & 0.04 & S \\
\hline Site & EOC & 17.136 & 4 & 4.28 & 0.05 & 0.99 & NS \\
\hline \multirow{2}{*}{ Education } & POC & 6191.35 & 6 & 1031.89 & 5.08 & 0.000 & S \\
\hline \multirow{2}{*}{ Survival } & EOC & 833.70 & 6 & 138.95 & 1.78 & 0.10 & NS \\
\hline & POC & 6434.40 & 3 & 2144.80 & 10.83 & 0.000 & $\mathrm{~S}$ \\
\hline Age & EOC & 183.39 & 3 & 61.13 & 0.76 & 0.51 & NS \\
\hline & POC & 324.15 & 3 & 108.05 & 0.46 & 0.70 & NS \\
\hline POC- Pro & EOC & 164.15 & 3 & 54.05 & 0.67 & 0.57 & NS \\
\hline
\end{tabular}

POC- Problem-oriented coping, EOC- Emotion-oriented coping, S- Significant, NS - Not significant

Table 3: T-test shows mean squares and SD on problem-oriented coping for different treatment levels

\begin{tabular}{lcccccc}
\hline Variables & Treatment & N & Mean & SD & T-value & $P$-value \\
\hline POC & Palliative & 6 & 62.50 & 14.57 & -2.361 & 0.02 \\
\hline POC & Surgery & 69 & 77.72 & 15.19 & & 0.002 \\
\hline POC & Palliative & 6 & 62.50 & 14.57 & -3.248 & \\
\hline & RT+Sur & 34 & 80.59 & 12.25 & & 0.02 \\
\hline
\end{tabular}

RT - Radiation therapy, Sur - Surgery 
Table 4: T-test shows mean squares and SD on problem-oriented coping for different educational status

\begin{tabular}{llllllc} 
Variable & Education & $\mathrm{N}$ & Mean & SD & T-value & $P$-value \\
\hline POC & Illiterates & 62 & 70.00 & 14.67 & -2.599 & 0.01 \\
\hline POC & Primary & 68 & 76.59 & 15.35 & & 0.000 \\
\hline & Illiterates & 62 & 70.00 & 14.67 & -3.917 & \\
\hline POC & Secondary & 27 & 83.44 & 15.35 & & 0.000 \\
\hline POC & Illiterates & 62 & 70.00 & 14.67 & -5.091 & 0.04 \\
\hline & Graduates & 19 & 88.00 & 8.28 & -2.072 & \\
\hline POC & Primary & 68 & 76.59 & 14.22 & & 0.001 \\
\hline
\end{tabular}

illiterates scored 70 on POC, the primary level scored 76, the secondary level 83 and the graduates had the highest POC score - 88. This indicates that education can make a difference in the preference of POC. Also, for each educational level, there was a significant difference in the preference for POC.

\section{Site [Table 5]}

With respect to site of disease, the larynx cancer patients $(\mathrm{M}=85.09)$ were found to have a high POC and less EOC. The patients with cancer of the parotid gland have shown high POC when compared to cheek cancer patients.

\section{Gender}

The ' $t$ ' test was employed to find out the the preference of coping with respect to gender difference [Table 6].

\section{Discussion}

The findings of this study endorse the fact that for every patient, irrespective of site, treatment, survival, age and education, cancer has the same significance and that they endure similar emotional trauma. ${ }^{[12]}$ Age and period of survival, however, have shown to be immaterial with respect to the coping strategies. A study by Derks revealed that younger HNC patients used more of POC and older patients used more of EOC. ${ }^{[7]}$

A study by Morton revealed that patients learned to cope well with dysfunction and disability by adjusting their lifestyles so that overall QOL was not related to treatment received. ${ }^{[12]}$ In the present study, a difference was observed between the treated and untreated patients and not within the different treatment modalities. The assurance of a definitive treatment gives confidence to patients and enhances their optimistic orientation and also ability to take control over the situation. ${ }^{[13]}$ Studies show that social support and adequate information

Table 5: T-test shows mean squares and SD on problem-oriented coping for different sites

\begin{tabular}{|c|c|c|c|c|c|c|}
\hline Variable & Site & $\mathrm{N}$ & Mean & SD & T-value & $P$-value \\
\hline \multirow[t]{2}{*}{ POC } & Cheek & 44 & 67.80 & 16.60 & -4.16 & 0.000 \\
\hline & Larynx & 22 & 85.09 & 14.36 & & \\
\hline \multirow[t]{2}{*}{ EOC } & Cheek & 44 & 32.39 & 8.92 & 2.693 & 0.009 \\
\hline & Larynx & 22 & 26.64 & 6.40 & & \\
\hline \multirow[t]{2}{*}{ POC [only] } & Cheek & 44 & 67.80 & 16.60 & -3.61 & 0.001 \\
\hline & Others & 33 & 81.30 & 15.68 & & \\
\hline \multirow[t]{2}{*}{ POC [only] } & Cheek & 44 & 67.80 & 16.60 & -3.40 & 0.001 \\
\hline & Thyroid & 33 & 79.36 & 11.84 & & \\
\hline \multirow[t]{2}{*}{ POC [only] } & Tongue & 20 & 73.40 & 8.05 & -3.20 & 0.003 \\
\hline & Larynx & 22 & 85.09 & 14.36 & & \\
\hline \multirow[t]{2}{*}{ POC [only] } & Thyroid & 33 & 79.36 & 11.84 & 1.984 & 0.05 \\
\hline & Tongue & 20 & 73.40 & 8.05 & & \\
\hline \multirow[t]{2}{*}{ POC [only] } & Tongue & 20 & 73.40 & 8.05 & -2.088 & 0.04 \\
\hline & Others* & 33 & 81.30 & 15.68 & & \\
\hline \multirow[t]{2}{*}{ EOC [only] } & Thyroid & 33 & 30.64 & 7.15 & 2.119 & 0.03 \\
\hline & Larynx & 22 & 26.64 & 6.40 & & \\
\hline \multirow[t]{2}{*}{ EOC [only] } & Larynx & 22 & 26.64 & 6.40 & -1.987 & 0.05 \\
\hline & Others & 33 & 30.12 & 6.36 & & \\
\hline
\end{tabular}

*Others - parotid gland, Salivary gland, Nose, Nasopharynx, Lip and eye 
Table 6: T-test shows mean squares and SD on problem- and emotion-oriented coping for male and female

\begin{tabular}{lllllll}
\hline Variable & Gender & $\mathrm{N}$ & Mean & SD & t-value & $P$-value \\
\hline POC & Male & 106 & 78.90 & 15.20 & 2.557 & 0.01 \\
\hline EOC & Female & 70 & 73.00 & 14.63 & & 0.006 \\
\hline & Male & 106 & 29.22 & 9.37 & -2.790 & \\
\hline
\end{tabular}

about the treatment lead to better coping methods and this enhances the quality of life. ${ }^{[3,14]}$

Patients treated with radiation therapy and surgery were found to have higher scores on POC strategies. On the contrary, advanced cancer patients preferred more of EOC than POC. Once the disease is beyond the scope of a cure, patients are on symptomatic and supportive treatment. This knowledge itself can heighten their helplessness. Patients who are newly diagnosed and those with advanced disease do not have a definite treatment solution at that given point. This may trigger their insecurity, lack of control and pessimism, which enhance their preferences for more of emotional coping and less of the problem approach. An earlier study with HNC also supports this evidence. ${ }^{[15]}$

The result of this study indicated that the site of cancer also influences the way an individual views his capacity to deal with the situation. This is supported by a study that has shown that there were significant differences in the preference of coping among the different sites of cancer. $^{[16]}$ The head and neck region plays a significant role in the outcome. This is not only due to the inherent biological heterogeneity of the tumors concerned but also due to the type of disability it confers in the post-therapy scenario. ${ }^{[17]}$ Organs like tongue and larynx have a significant functional disability, while others like buccal mucosa may contribute more to cosmetic disfigurement when surgery is applied. ${ }^{[19,20]}$ With respect to emotional-oriented shift, there is a significant difference between cheek $v s$ larynx, thyroid $v s$ larynx and larynx $v$ s other cancers at $P<0.01, P=0.03$ and $P=0.05$ levels respectively. While larynx patients have a high POC, patients suffering from cancer of cheek and other sites have a high EOC.

The larynx patients, at the Cancer Institute, receive focussed supportive care, better rehabilitation methods like speech therapy and social support through interacting with other patients at the laryngectomy welfare association meetings. This aids patient-to-patient care, group therapy, etc. This amount of support and clarity of prognosis can enhance confidence, optimistic orientation and a fighting spirit which makes patients prefer problem solving approaches in dealing with situations. A study by Chaturvedi also supports this result. Compared to laryngeal cancer, those with oral cancer more often had concerns about current illness, subjective evaluation of health, eating and chewing, social interaction, pain and disfigurement. ${ }^{[3]}$ Results also show that educational status has a significant association with coping strategies. It was found that, higher the education, higher the POC.

No difference was observed amongst the patients with different survival periods. Moreover, irrespective of the number of years of survival, the fear of recurrence remains the same. ${ }^{[18]}$ This is evident in a few studies, which suggest that cancer patients are plagued by worry over areas such as risk of recurrence. ${ }^{[19-22]}$

In conclusion, HNC patients adopt both EOC and POC during the course of the illness. The preferences in the EOC did not differ among the HNC patients with respect to the site, treatment, age, education and survival. The preferences in the POC differed among the patients with different sites, literacy level and treatment. On the other hand, the survival or age did not show any difference on either of the coping preferences. Literates, males and treated patients preferred more of POC compared to other groups.

\section{Limitations}

1. This is a single-institutional study.

2. The sample is highly heterogeneous and the sample size in each group is small.

3. A more systematic randomized study can help in identifying the preferences in a better way.

4. The results of the study cannot be generalized to other patients with cancer at other sites.

5. The coping strategy tested here is based on one model. Other coping models need to be explored.

\section{Future directions}

- The coping preferences in relation to QOL need to be studied.

- Further examination using a large sample of patients 
with HNC is warranted.

- The impact of the psychological interventions shifting from EOC to POC needs to be studied further.

\section{References}

1. Allison PJ, Nicolau B, Edgar L, Archer J, Black M, Hier M. Head and neck cancer patients coping strategies: Results of a feasibility study. Oral Oncol 2004;40:538-44.

2. Smeltzer SC, et al. Textbook of medical surgical nursing. $8^{\text {th }}$ ed.

3. Chaturvedi SK, Shenoy A, Prasad KM, Senthilnathan SM, Premlatha BS. Concerns, coping and quality of life in head and neck cancer patients. Support Care Cancer 1996;4:186-90.

4. Burgess C, Morris T, Pettingale KW. Psychological response to cancers diagnosis-II. Evidence for coping styles (Coping styles and cancer diagnosis). J Psychosom Res 1988;32:263-72.

5. Classen C, Koopman C, Angell K, Spiegel D. Coping styles associated with psychological adjustment to advanced breast cancer. Health Psychol 1996;15:434-7.

6. Friedman LC. Predictors of psychosocial adjustment to breast cancer. J Psychosoc Oncol 1988;6:75-94.

7. Lazarus RS, Folkman S. Stress appraisal and coping. Springer: New York; 1984.

8. Derks W, Leeuw JR, Hordijk GJ, Winnubst JA. Differences in coping style and locus of control between older and younger patients with head and neck cancer. Clin Otolaryngol 2005;30: 186-92.

9. List MA, Lee Rutherford J, Stracks J, Haraf D, Kies MS, Vokes EE. An exploration of the pretreatment coping strategies of patients with carcinoma of the head and neck. Cancer 2002;95:98-104.

10. He G, Liu S. Quality of life and coping styles in Chinese nasopharyngeal cancer patients after hospitalization. Cancer Nursing 2005;28:179-86.

11. Relic A, Mazemda P, Arens C, Koller M, Glanz H. Investigating quality of life and coping resources after laryngectomy. Eur Arch Otorhinolaryngol 2001;258:514-7.

12. Jalowiec A, Powers JM. Stress and Coping In: Hypertensive And Emergency Room Patients. Nursing Res 1981;30:10-5.

13. Lampic C, Wennberg A, Schill JE, Glimelius B, Brodin O, Sjoden PO. Coping, psychosocial well-being and anxiety in cancer patients at follow-up visits. Acta Oncologica 1994;33:887-94.

14. Morton RP. Studies in the quality of life of head and neck cancer patients: Results of a two-year longitudinal study and a comparative cross-sectional cross-cultural survey. Laryngoscope 2003;113:1091-103.

15. David HP. Coping with cancer. A personal odyssey. Patient Educ Couns 1999;37:293-7.

16. Ramirez MJ, Ferriol EE, Domenech FG, Llatas MC, Suarez-Varela MM, Martinez RL. Psychosocial adjustment in patients surgically treated for laryngeal cancer. Otolaryngol Head Neck Surg 2003; 129:92-7.

17. Fang FM, Chien CY, Kuo SC, Chiu HC, Wang CJ. Changes in quality of life of head-and-neck cancer patients following postoperative radiotherapy. Acta Oncol 2004;43:571-8.

18. Watson M. Psychosocial issues in cancer. Curr Sci 2001;81:437-7.

19. Hess M, Kugler J, Kalveram KT, Vosteen KH. The effect of functional impairments and autonomic symptoms on the quality of life after the therapy of tumors in the ENT area. Laryngorhinootologie 1990;69:647-52.

20. Pourel N, Peiffert D, Lartigau E, Desandes E, Luporsi E, Conroy T. Quality of life in long-term survivors of oropharynx carcinoma. Int J Radiat Oncol Biol Phys 2002;54:742-51.

21. Cella D, Tross S. Psychological adjustment to survival from Hodgkin's disease. J Consult Clin Psychol 1986;54:616-22.

22. Fobiar P, Hoppe RT, Bloom J, Cox R, Varghese A, Spiegel D. Psychosocial problems among survivors of Hodgkin's disease. J Clin Oncol 1986;4:805-14.

23. Mullan F. Re-entry: The educational needs of the cancer survivor. Health Educ Qu 1984;10:88-94.

24. Welch-McCaffrey D. Cancer, anxiety and quality of life. Chapter 3, CRC Press: Boca Raton, FL; 1991. 